\title{
Screening and analysis of breast cancer genes regulated by the human mammary microenvironment in a humanized mouse model
}

\author{
MINGJIE ZHENG ${ }^{1 *}$, JUE WANG $^{1 *}$, LIJUN LING $^{1 *}$, DANDAN XUE $^{2}$, SHUI WANG $^{1}$ and YI ZHAO ${ }^{1}$ \\ ${ }^{1}$ Department of Breast Surgery, The First Affiliated Hospital of Nanjing Medical University, Nanjing, Jiangsu 210029; \\ ${ }^{2}$ Department of Sugery, Affiliated Hospital of Nantong University, Nantong, Jiangsu 226018, P.R. China
}

Received December 29, 2014; Accepted March 9, 2016

DOI: $10.3892 / \mathrm{ol} .2016 .5310$

\begin{abstract}
Tumor microenvironments play critical regulatory roles in tumor growth. Although mouse cancer models have contributed to the understanding of human tumor biology, the effectiveness of mouse cancer models is limited by the inability of the models to accurately present humanized tumor microenvironments. Previously, a humanized breast cancer model in severe combined immunodeficiency mice was established, in which human breast cancer tissue was implanted subcutaneously, followed by injection of human breast cancer cells. It was demonstrated that breast cancer cells showed improved growth in the human mammary microenvironment compared with a conventional subcutaneous mouse model. In the present study, the novel mouse model and microarray technology was used to analyze changes in the expression of genes in breast cancer cells that are regulated by the human mammary microenvironment. Humanized breast and conventional subcutaneous mouse models were established, and orthotopic tumor cells were obtained from orthotopic tumor masses by primary culture. An expression microarray using Illumina HumanHT-12 v4 Expression BeadChip and database analyses were performed to investigate changes in gene expression between tumors from each microenvironment. A total of 94 genes were differentially expressed between the primary cells cultured from the humanized and conventional mouse models. Significant upregulation of genes that promote cell proliferation and metastasis or inhibit apoptosis, such as SH3-domain binding protein 5 (BTK-associated), sodium/chloride cotransporter 3 and periostin, osteoblast specific factor, and genes that promote angiogenesis, such
\end{abstract}

Correspondence to: Professor Shui Wang or Dr Yi Zhao, Department of Breast Surgery, The First Affiliated Hospital of Nanjing Medical University, 300 Guangzhou Road, Nanjing, Jiangsu 210029, P.R. China

E-mail:ws0801@hotmail.com

E-mail: doctorzhaoyi@sina.cn

*Contributed equally

Key words: breast cancer, microenvironments, humanized mouse model, gene expression, microarray as KIAA1618, was also noted. Other genes that restrain cell proliferation and accelerate cell apoptosis, including tripartite motif containing TRIM36 and NES1, were downregulated. The present results revealed differences in various aspects of tumor growth and metabolism between the two model groups and indicated the functional changes specific to the human mammary microenvironment.

\section{Introduction}

Over previous years, tumor microenvironments have been recognized to play important roles in regulating tumor progression (1). The tumor microenvironment includes interwoven stroma and cells, such as fibroblasts, adipocytes, myoepithelial cells, inflammatory cells and endothelial cells, in addition to the secreted factors of the stroma and cells. The tumor microenvironment promotes tumor growth, stimulates angiogenesis, increases inflammatory response and induces metastasis (1-4).

Mouse models of human cancer play a crucial role in cancer research and the screening of anticancer agents $(5,6)$. However, although certain agents show consistent and potent anticancer activity in mouse models, the response rate among patients in phase I clinical trials is $<10 \%(7,8)$. Therefore, it has been hypothesized that current mouse models cannot accurately mimic the humanized tumor microenvironment (9).

Previously, a humanized mouse model of breast cancer, in which normal human breast tissue was implanted under the sub-dermis of mice, was developed. Human breast cancer cell lines were then injected into the implants (10). Compared with the conventional subcutaneous (SUB) mouse model, in which human breast cancer cells are directly injected under the subdermis, this novel human breast tissue-derived (HB) mouse model was hypothesized to more accurately mimic the interactions between the human mammary microenvironment and human breast cancer cells (11). To obtain detailed characterization of this model, tumor formation and metastasis were compared between the HB and SUB mouse models (3). Orthotopic tumor cells were obtained from orthotopic tumor masses of these two models by primary culture and evaluated in in vitro experiments. In vivo, cellular and molecular experiments compared the biology of human breast cancer cells. It was confirmed that human breast cancer cells demonstrated better growth in the human mammary microenvironment compared with the mouse subcutaneous microenvironment. 
As expected, the human-specific microenvironment more accurately regulates the proliferation and metastasis of human breast cancer cells (12). These initial findings prompted the investigation of the mechanisms underlying the regulatory genes and pathways specific to the human mammary microenvironment.

In the present study, the HB and SUB mouse models were established, and orthotopic tumor cells were obtained from orthotopic tumor masses by primary culture. Gene expression profiles were evaluated by microarray to screen altered gene expression in the primary breast cancer cells that were regulated by the human mammary microenvironment and subcutaneous microenvironment. Furthermore, differentially expressed genes were validated by reverse transcription-quantitative polymerase chain reaction (RT-qPCR) and analyzed using several databases.

\section{Materials and methods}

Cell culture. The human breast cancer SUM1315 cell line was provided by Dr Stephen Ethier (University of Michigan, Ann Arbor, MI, USA) were labeled with green fluorescent protein (GFP), as previously described (13). GFP-labeled SUM1315 cells (G1315) were cultured in Gibco Dulbecco's modified Eagle's medium (DMEM; Thermo Fisher Scientific, Inc.) supplemented with $10 \%$ Gibco fetal bovine serum (FBS; Thermo Fisher Scientific, Inc.) and $1 \%$ penicillin-streptomycin solution (Gibco; Thermo Fisher Scientific, Inc.) in a humidified atmosphere of $5 \% \mathrm{CO}_{2}$ at $37^{\circ} \mathrm{C}$.

Animals. Female severe combined immunodeficiency (SCID) CB-17IcrCrl-scidbgBR mice aged 4-6 weeks were purchased from the Model Animal Research Center of Nanjing University (Nanjing, Jiangsu, China). The SCID mice were kept under specific pathogen-free, temperature-controlled conditions. Cages, bedding and drinking water were autoclaved and changed regularly. Food was sterilized by irradiation. The mice were maintained in a daily cycle of $12 \mathrm{~h}$ period of lightness and darkness. In total, 6 mice were randomly divided into two groups to establish the HB and SUB mouse models.

Development of the humanized HB models. Normal human breast tissues were obtained in May 2013 from elective breast reduction mammoplasty surgery of 3 patients at the The First Affliated Hospital of Nanjing Medical University (Nanjing, Jiangsu, China). Sample collection was performed in accordance with the ethical guidelines of the Declaration of Helsinki (14), and approved by the Ethics and Research Committee of the First Affiliated Hospital with Nanjing Medical University (Nanjing, Jiangsu, China). Breast tissues were sliced under sterile conditions into pieces $\sim 4 \times 4 \times 4 \mathrm{~mm}$ in size. Three pieces were selected randomly for histological examination to exclude primary malignant disease. Small pieces of the human breast tissues were placed in ice-cold PBS until implantation into SCID mice. Implantation was finished within $6 \mathrm{~h}$ of mammoplasty surgery. Prior to implantation, the mice were anesthetized by intraperitoneal injection with $1 \%$ pentobarbital sodium (10 $\mu \mathrm{l} / \mathrm{g}$ body weight; Sigma-Aldrich, Steinheim, Germany). Surgical procedures were modified from a previous method (15), which transplanted human gastric tissue, whereas in the present study, human mammary tissue was transplanted. Briefly, 5-6-mm scalpel incisions were made in the skin of the left mid-dorsal flank of mice, through which 5 human breast tissue fragments were implanted subcutaneously. The mice received gentamycin in the drinking water (800,000 U/l) until 1 week following the implantation. All in vivo experiments were conducted according to the Guide for the Care and Use of Laboratory Animals (16) and approved by the Animal Care and Use Committee of Nanjing Medical University.

Injection of human breast cancer cells into SCID mice. Human breast cancer cells ( $80 \%$ confluent) were cultured in fresh DMEM supplemented with $10 \% \mathrm{FBS}$ and $1 \%$ penicillin-streptomycin solution for $24 \mathrm{~h}$. The cells were harvested with $0.25 \%$ tyrosine and $0.02 \%$ disodium EDTA (Gibco; Thermo Fisher Scientific, Inc.), washed in medium, counted, and re-suspended in PBS. Human breast cancer cells $\left(5 \times 10^{5}\right)$ in $0.2 \mathrm{ml}$ PBS were injected into the implanted human breast tissues $\sim 1$ week subsequent to implantation of the human breast tissue. Equal amounts of tumor cells were injected into the left mid-dorsal flank subcutaneously to form the SUB control group.

Primary cultured tumor cells. All mice were sacrificed 5 weeks subsequent to injection of human breast cancer cells. Orthotopic tumor masses were collected under sterile conditions. One section was used for histological examination and another section was used for primary culture. Primary culture was conducted as previously described (13). Briefly, sections of the orthotopic tumor masses $(2 \times 2 \times 2 \mathrm{~mm})$ were washed in sterile PBS with $1 \%$ penicillin-streptomycin three times, and broken into small tumor pieces using scissors (1-2 Hz for $10 \mathrm{~min}$ ) in $0.2 \mathrm{ml}$ PBS. PBS $(3 \mathrm{ml})$ was then added to the mixture, and the samples were centrifuged at $129 \times \mathrm{g}$ for $5 \mathrm{~min}$ in a centrifuge (Eppendorf, Hamburg, Germany). Subsequent to discarding the supernatant, the sedimentary tumor pieces were re-suspended in $5 \mathrm{ml} \mathrm{DMEM}$ and transferred to $10 \mathrm{~cm}$ dishes. Another $10 \mathrm{ml}$ DMEM was added into the dishes for routine cell culture 16 h later. Following 5-7 days of culture, breast cancer cells from small tumor pieces adhered to dishes and the small tumor pieces were discarded. GFP-labeled primary cultured tumor cells were grown to $\sim 80 \%$ confluency and harvested for fluorescence activated cell sorting (FACS) 1 week later. FACS analysis was conducted according to the manufacturer's protocol (FACSCalibur; BD Biosciences, Franklin Lakes, NJ, USA). The primary cultured human breast cancer cells were finally obtained, as follows: primary cultured G1315 cells from HB mouse models (pri-HB-1315); and primary cultured G1315 cells from SUB mouse models (pri-SUB-1315).

Total RNA extraction. Total RNA was isolated from primary cells using TRIzol ${ }^{\circledR}$ reagent (Thermo Fisher Scientific, Inc.) combined with the Qiagen RNeasy Lipid Tissue kit protocol (Qiagen, Valencia, CA, USA), according to the manufacturer's recommendation. RNA concentrations and the A260 nm/A280 $\mathrm{nm}$ ratio were assessed using a NanoDrop 1000 spectrophotometer (Thermo Fisher Scientific, Inc., Waltham, MA, USA). 
Table I. Primer sequences for quantitative polymerase chain reaction.

\begin{tabular}{|c|c|c|}
\hline Gene & Sequence, 5'-3' & Amplicon size, bp \\
\hline SH3BP5 & & 272 \\
\hline Sense & TGTGTCCCTGTCAGAGTTTG & \\
\hline Antisense & СТСTTCССTTTGAGCACTGT & \\
\hline TRIM36 & & 336 \\
\hline Sense & AGGGTTCAATCTGTAGTCC & \\
\hline Antisense & GAGAACGGAGCCATTCTTGT & \\
\hline RPL32 & & 221 \\
\hline Sense & CGTAACTGGCGGAAACCC & \\
\hline Antisense & TTGGAGGAAACATTGTGAGC & \\
\hline BCL10 & & 234 \\
\hline Sense & CCGAGGAGGACCTCACT & \\
\hline Antisense & GAATAGATTCAACAAGGGTGT & \\
\hline KIAA1618 & & 174 \\
\hline Sense & стССТGСТСТTGСТTCTGG & \\
\hline Antisense & GACGCCATTGTGGAGTTATT & \\
\hline LRTM1 & & 113 \\
\hline Sense & CCAGTGTGATTGTCCTGCTCC & \\
\hline Antisense & GGAAGGGATTTCGGCCAGA & \\
\hline BPTF & & 208 \\
\hline Sense & GTCAACAAAGTGGTGTACGATGA & \\
\hline Antisense & TGCAGTAACTGGCGTCGTC & \\
\hline FGF13 & & 113 \\
\hline Sense & GTTACCAAGCTATACAGCCGAC & \\
\hline Antisense & ACAGGGATGAGGTTAAACAGAGT & \\
\hline PWWP2A & & 192 \\
\hline Sense & CTTGTCGTGTCGTTCCGCTT & \\
\hline Antisense & ACCATTTGCTTCACACTTGACTT & \\
\hline CCDC113 & & 321 \\
\hline Sense & GCAGGTTCTCAATGCCTACA & \\
\hline Antisense & CGATTCCAAGCCTTACGATG & \\
\hline$\beta$-actin & & 369 \\
\hline Sense & GCTGTGCTATCCCTGTACGC & \\
\hline Antisense & TGCCTCAGGGCAGCGGAACC & \\
\hline
\end{tabular}

SH3BP5, SH3-domain binding protein 5 (BTK-associated); TRIM36, tripartite motif containing 36; RPL32, ribosomal protein L32; BCL10, B-cell CLL/lymphoma 10; LRTM1, leucine-rich repeats and transmembrane domains 1; BPTF, bromodomain PHD finger transcription factor; FGF13, fibroblast growth factor 13; PWWP2A, PWWP domain containing 2A; CCDC113, coiled-coil domain containing 113.

Microarray expression analysis. The HumanHT-12 v4 expression microarray (Illumina, Inc., San Diego, CA, USA) platform was used to measure expression levels in each unpooled specimen, according to the manufacturer's instructions. Briefly, subsequent to purification of RNA using an RNeasy Mini kit, 500 ng of total RNA was amplified and biotin-labeled with the Ambion Illumina ${ }^{\circledR}$ Total Prep RNA Amplification kit (Thermo Fisher Scientific, Inc.). Labeled cRNAs were hybridized to the Illumina HumanHT-12 V4 expression BeadChip (Illumina, Inc.) and imaged using an Iscan system. Raw data was obtained using GenomeStudio Software (Illumina, Inc.).
$R T-q P C R$. RT-qPCR was used to verify the gene expression profile results. In total, 10 target genes were selected. PCR for the reference gene $\beta$-actin and target genes was performed for each cDNA sample, as in the microarray. All PCR reactions were performed on the Eppendorf MasterCycler RealPlex (Eppendorf) using the fluorescent SYBR Green I methodology with SYBR ${ }^{\circledR}$ Premix Ex Taq ${ }^{\mathrm{TM}}$ (Takara, Dalian, Liaoning, China), according to the manufacturer's instructions. The thermal cycling conditions consisted of $10 \mathrm{~min}$ at $95^{\circ} \mathrm{C}$ and 40 cycles of $10 \mathrm{sec}$ denaturation at $95^{\circ} \mathrm{C}, 15 \mathrm{sec}$ annealing at $58^{\circ} \mathrm{C}$, and $45 \mathrm{sec}$ extension at $72^{\circ} \mathrm{C}$. The primer sequences for RT-qPCR are listed in Table I. The mRNA quantities were 
Table II. Top 40 microarray probes with differential expression between pri-HB-1315 cells and pri-SUB-1315 cells.

\begin{tabular}{|c|c|c|c|c|c|}
\hline Probe ID & Entrez gene ID & Gene symbol & Regulation & Fold change & P-value \\
\hline ILMN_3242632 & 474149 & TTTY4B & Up & 7.703716 & 0.0001 \\
\hline ILMN_1704070 & 8915 & BCL10 & $\mathrm{Up}$ & 2.487273 & 0.0004 \\
\hline ILMN_1901555 & N/A & HS.160572 & Down & 2.335326 & 0.0006 \\
\hline ILMN_1775520 & 29070 & CCDC113 & Down & 4.154990 & 0.0015 \\
\hline ILMN_1814773 & 9467 & SH3BP5 & Up & 7.974966 & 0.0018 \\
\hline ILMN_3241612 & 100134160 & LOC100134160 & $\mathrm{Up}$ & 3.376311 & 0.0020 \\
\hline ILMN_3242508 & 100128569 & C19ORF71 & Up & 7.282197 & 0.0025 \\
\hline ILMN_1886092 & N/A & HS.383564 & Up & 6.619400 & 0.0032 \\
\hline ILMN_1771403 & 114825 & PWWP2A & Down & 3.021580 & 0.0036 \\
\hline ILMN_1911594 & N/A & HS.544379 & Down & 2.340812 & 0.0041 \\
\hline ILMN_1702526 & 56985 & C17ORF48 & $\mathrm{Up}$ & 2.091994 & 0.0042 \\
\hline ILMN_3274677 & 644384 & LOC644384 & Up & 4.481474 & 0.0055 \\
\hline ILMN_1800302 & 57408 & LRTM1 & Up & 7.108377 & 0.0058 \\
\hline ILMN_1659202 & 8708 & B3GALT1 & Down & 5.387461 & 0.0066 \\
\hline ILMN_1798636 & 6161 & RPL32 & Up & 2.159039 & 0.0076 \\
\hline ILMN_1674891 & 57714 & KIAA1618 & $\mathrm{Up}$ & 7.141605 & 0.0080 \\
\hline ILMN_3243506 & 100132826 & LOC100132826 & Down & 8.624489 & 0.0082 \\
\hline ILMN_1681605 & 649415 & LOC649415 & Up & 8.105968 & 0.0084 \\
\hline ILMN_2108699 & 3559 & IL2RA & Up & 9.412559 & 0.0084 \\
\hline ILMN_1911964 & N/A & HS.573253 & Up & 2.625982 & 0.0092 \\
\hline ILMN_1699179 & 2186 & BPTF & Down & 6.746059 & 0.0097 \\
\hline ILMN_1895686 & N/A & HS.159049 & $\mathrm{Up}$ & 7.099847 & 0.0103 \\
\hline ILMN_2196328 & 10631 & POSTN & Up & 10.754470 & 0.0105 \\
\hline ILMN_1787951 & 64792 & RABL5 & Down & 6.704001 & 0.0105 \\
\hline ILMN_1914025 & N/A & HS.98588 & Down & 3.775930 & 0.0106 \\
\hline ILMN_2189614 & 57730 & ANKRD36B & Down & 2.517973 & 0.0109 \\
\hline ILMN_1727852 & 643339 & LOC643339 & Down & 6.640404 & 0.0112 \\
\hline ILMN_1726762 & 440577 & LOC440577 & Down & 6.419832 & 0.0117 \\
\hline ILMN_1691217 & 54768 & HYDIN & Down & 5.483594 & 0.0123 \\
\hline ILMN_1904111 & N/A & HS.553291 & Up & 3.240943 & 0.0124 \\
\hline ILMN_1667018 & 59272 & ACE2 & Up & 2.472109 & 0.0124 \\
\hline ILMN_1674580 & 55521 & TRIM36 & Down & 10.185940 & 0.0128 \\
\hline ILMN_1767992 & 9990 & SLC12A6 & Up & 2.305506 & 0.0152 \\
\hline ILMN_1778098 & 650296 & LOC650296 & Down & 5.878049 & 0.0153 \\
\hline ILMN_2102330 & 1296 & COL8A2 & Up & 13.115850 & 0.0158 \\
\hline ILMN_3236704 & 100133420 & LOC100133420 & Down & 5.030801 & 0.0159 \\
\hline ILMN_1671777 & 2258 & FGF13 & Down & 13.555210 & 0.0160 \\
\hline ILMN_1747344 & 3563 & IL3RA & Down & 2.112653 & 0.0172 \\
\hline ILMN_3248591 & 4053 & LTBP2 & Down & 2.363452 & 0.0182 \\
\hline ILMN_1748281 & 5602 & MAPK10 & Up & 6.113067 & 0.0183 \\
\hline
\end{tabular}

analyzed in triplicate and normalized against $\beta$-actin as a control gene. The results are expressed as relative gene expression using the $2^{-\Delta \Delta \mathrm{Cq}}$ method (17).

Statistical analysis. All data were analyzed using the SPSS software, version 12.0 (SPSS, Chicago, IL, USA). Paired $t$-test was used to screen differential genes in the microarray. Student's $t$-test was used for the analysis of the qPCR results. $\mathrm{P}<0.05$ was considered to indicate a statistically significant difference.

\section{Results}

Global changes in gene expression. A total of 94 genes were differentially expressed in the pri-HB-1315 cells cultured from the HB model and the pri-SUB-1315 cells cultured from the SUB model (Table II). Gene ontology (GO) analysis $(18,19)$ was applied to obtain insight into the biology associated with the stereotypic differences between the pri-HB-1315 and pri-SUB-1315 cells. Significant enrichment of 16 molecular functions, 6 distinct biological processes and 2 cellular 
Table III. Gene ontology analyses: Molecular functions, biological processes and cellular components associated with genes that are differentially expressed between pri-HB-1315 and pri-SUB-1315 cells.

\begin{tabular}{|c|c|c|c|}
\hline Molecular function & $\begin{array}{l}\text { Total number } \\
\text { of genes, } \mathrm{n}\end{array}$ & $\begin{array}{l}\text { Number of differentially } \\
\text { expressed genes, } \mathrm{n}\end{array}$ & P-value \\
\hline c-Jun N-terminal kinase activity & 15 & 12 & $<0.0001$ \\
\hline SAP kinase activity & 15 & 12 & $<0.0001$ \\
\hline MAP kinase activity & 50 & 14 & $<0.0001$ \\
\hline $\begin{array}{l}\text { Receptor signaling protein } \\
\text { serine/threonine kinase activity }\end{array}$ & 106 & 14 & $<0.0001$ \\
\hline Receptor signaling protein activity & 173 & 14 & $<0.0001$ \\
\hline Signal transducer activity & 2,557 & 24 & $<0.0001$ \\
\hline Molecular transducer activity & 2,557 & 24 & $<0.0001$ \\
\hline Protein serine/threonine kinase activity & 956 & 14 & $<0.0001$ \\
\hline $\begin{array}{l}\text { Phosphotransferase activity, } \\
\text { alcohol group as acceptor }\end{array}$ & 1,859 & 18 & 0.0002 \\
\hline Interleukin-1 receptor activity & 22 & 4 & 0.0002 \\
\hline Growth factor activity & 224 & 7 & 0.0007 \\
\hline Dopamine receptor activity & 9 & 3 & 0.0007 \\
\hline Kinase activity & 2,106 & 18 & 0.0007 \\
\hline Cytokine receptor activity & 149 & 6 & 0.0008 \\
\hline Protein kinase activity & 1,520 & 15 & 0.0010 \\
\hline $\begin{array}{l}\text { Transferase activity, transferring } \\
\text { phosphorus-containing groups }\end{array}$ & 2,517 & 19 & 0.0018 \\
\hline \multicolumn{4}{|l|}{ Biological process } \\
\hline Epithelial cell proliferation & 72 & 5 & 0.0006 \\
\hline Camera-type eye morphogenesis & 129 & 5 & 0.0065 \\
\hline Cytokine biosynthetic process & 22 & 3 & 0.0088 \\
\hline Cytokine metabolic process & 24 & 3 & 0.0109 \\
\hline Eye morphogenesis & 162 & 5 & 0.0167 \\
\hline Interleukin- 2 biosynthetic process & 5 & 2 & 0.2168 \\
\hline \multicolumn{4}{|l|}{ Cellular component } \\
\hline Large ribosomal subunit & 87 & 4 & 0.2145 \\
\hline Collagen & 176 & 5 & 0.2168 \\
\hline
\end{tabular}

SAP, stress-activated protein; MAP, mitogen-activated protein.

components was noted $(\mathrm{P}<0.05$; Table III). The Kyoto Encyclopedia of Genes and Genomes (20) yielded 7 pathways with significant differences $(\mathrm{P}<0.05$; Table IV).

$R T-q P C R$. A total of 10 genes were selected based upon microarray data and biological significance. Consistent with the microarray results, RT-qPCR confirmed the differential expression of 8 genes, with only 2 genes not demonstrating differential expression (Table V). Genes with significantly increased expression in the pri-HB-1315 group included SH3-domain binding protein 5 (BTK-associated), ribosomal protein L32 (RPL32), B-cell CLL/lymphoma 10 (BCL10), leucine-rich repeats and transmembrane domains 1 and KIAA1618 $(\mathrm{P}<0.05)$, while bromodomain PHD finger transcription factor (BPTF), tripartite motif containing 36
(TRIM36) and fibroblast growth factor 13 expression was significantly decreased in the pri-HB-1315 group $(\mathrm{P}<0.05)$. The other 2 genes, coiled-coil domain containing 113 and PWWP domain containing 2A, showed no significant difference in expression between the two groups.

\section{Discussion}

Several studies have examined the expression of genes in breast cancer cells co-cultured with stroma cells in in vitro models (21-24). However, in vitro models do not fully recapitulate all dynamics and dimensions of the tissue, and a complete picture of stromal-epithelial interactions requires linkages with studies in vivo. A novel mouse model that was implanted with human mammary tissue was previously established (10). 
Table IV. Pathways associated with differentially expressed genes in pri-HB-1315 and pri-SUB-1315 cells, as determined by Kyoto Encyclopedia of Genes and Genomes.

\begin{tabular}{lccc}
\hline Pathway name & $\begin{array}{c}\text { Total number of genes } \\
\text { in the pathway, } n\end{array}$ & $\begin{array}{c}\text { Number of differentially } \\
\text { expressed genes, } \mathrm{n}\end{array}$ & Adjusted P-value \\
\hline Cytokine-cytokine receptor interaction & 267 & 3 & 0.0073 \\
Apoptosis & 88 & 2 & 0.0076 \\
Hematopoietic cell lineage & 88 & 2 & 0.0076 \\
Insulin signaling pathway & 137 & 2 & 0.0176 \\
Jak-STAT signaling pathway & 155 & 2 & 0.0222 \\
Renin-angiotensin system & 17 & 1 & 0.0248 \\
Glycosphingolipid biosynthesis lacto & 26 & 1 & 0.0377 \\
and neolacto series & & & \\
\hline
\end{tabular}

Jak, Janus kinase; STAT, signal transducers and activators of transcription.

Table V. RT-qPCR and microarray results of tested genes compared between pri-HB-1315 and pri-SUB-1315 cells.

\begin{tabular}{|c|c|c|c|c|c|c|}
\hline \multirow[b]{2}{*}{ Gene } & \multicolumn{3}{|c|}{ RT-qPCR } & \multicolumn{3}{|c|}{ Microarray } \\
\hline & P-value & Fold change & $\begin{array}{c}\text { Direction of } \\
\text { change }^{\mathrm{a}}\end{array}$ & P-value & Fold change & $\begin{array}{c}\text { Direction of } \\
\text { change }^{\mathrm{a}}\end{array}$ \\
\hline SH3BP5 & 0.0001 & 1.8672 & $\uparrow$ & 0.0018 & 7.9750 & $\uparrow$ \\
\hline RPL32 & 0.0007 & 3.2819 & $\uparrow$ & 0.0076 & 2.1590 & $\uparrow$ \\
\hline BCL10 & 0.0001 & 1.8209 & $\uparrow$ & 0.0004 & 2.4872 & $\uparrow$ \\
\hline KIAA1618 & 0.0144 & 1.4825 & $\uparrow$ & 0.0080 & 7.1416 & $\uparrow$ \\
\hline LRTM1 & 0.0001 & 5.4124 & $\uparrow$ & 0.0058 & 7.1083 & $\uparrow$ \\
\hline TRIM36 & 0.0093 & 1.3868 & $\downarrow$ & 0.0015 & 10.1859 & $\downarrow$ \\
\hline BPTF & 0.0079 & 1.5733 & $\downarrow$ & 0.0096 & 6.7460 & $\downarrow$ \\
\hline FGF13 & 0.0005 & 2.0820 & $\downarrow$ & 0.0160 & 13.5552 & $\downarrow$ \\
\hline PWWP2A & 0.6673 & 1.0252 & $\downarrow$ & 0.0036 & 3.0215 & $\downarrow$ \\
\hline CCDC113 & 0.4450 & 1.2265 & $\downarrow$ & 0.0015 & 4.1550 & $\downarrow$ \\
\hline
\end{tabular}

${ }^{a}$ Direction of change denotes change in pri-HB-1315 cells. SH3BP5, SH3-domain binding protein 5 (BTK-associated); RPL32, ribosomal protein L32; BCL10, B-cell CLL/lymphoma 10; LRTM1, leucine-rich repeats and transmembrane domains 1; TRIM36, tripartite motif containing 36; BPTF, bromodomain PHD finger transcription factor; FGF13, fibroblast growth factor 13; PWWP2A, PWWP domain containing 2A; CCDC113, coiled-coil domain containing 113; RT-qPCR, reverse transcription-quantitative polymerase chain reaction.

As an in vivo model, it provides a humanized microenvironment and was shown to be more accurate than the conventional subcutaneous mouse model in mimicking human breast cancer cells and the human mammary microenvironment (12). In the present study, the novel mouse model and microarray technology was used to analyze the gene expression changes in breast cancer cells regulated by the human mammary microenvironment.

The expression levels of 94 identified genes were modulated by the human mammary microenvironment. Out of the 94 genes, several genes that promoted cell proliferation and metastasis or inhibited apoptosis were upregulated in the pri-HB-1315 group, including SH3BP5 (25), sodium/chloride cotransporter $3(26,27)$ and periostin, osteoblast specific factor $(28,29)$. Other genes that restrain cell proliferation and accelerate cell apoptosis were downregulated in the
pri-HB-1315 group, such as TRIM36 (30) and NES1 (31). In addition, genes that promote angiogenesis were upregulated, including KIAA1618 (32). RPL32 is a protein component of ribosomes, which are sites of protein synthesis (33). Increased expression of the RPL32 gene indirectly reflects the increased cell proliferation. Alterations in the expression of the aforementioned genes jointly induced and promoted the development of tumors in the pri-HB-1315 group with human mammary microenvironment. However, the upregulation of BCL10 (34) and the downregulation of BPTF (35) in the pri-HB-1315 group appear to correspond with the suppression of tumor progression. In addition, the function of certain genes, such as LTBP2 $(36,37)$ and RNA binding motif (RNP1, RRM) protein $3(38,39)$, remains controversial. Notably, certain genes, including angiotensin I converting enzyme 2 (40), which functions in cardiovascular disease, have been demonstrated to play 
important roles in other pathophysiological processes (41), but not tumor progression. In future studies, the putative function of these genes in tumor development and their upstream ligand factors in the human mammary microenvironment may be explored.

The mapping of genes to GO nodes is a powerful functional genomics tool suited to the analysis of microarray data, as it may be identified whether associated groups of genes from expression clustering share significant functional annotation in the GO database. As shown in Table II, the significantly enriched functional processes were summarized according to biological process, molecular function and cellular components. These changes indicated the existence of pathological processes globally induced by the human mammary microenvironment. The term definition and details were acquired from the GO network (42). Out of the 16 results of the GO analyses associated with molecular functions, several genes catalyze various reactions and promote cell metabolism, including c-Jun N-terminal kinase activity, mitogen-activated protein kinase activity and protein serine/threonine kinase activity. GOs which are expressed differently between two types of cells are termed 'enriched'. Other enriched GO analysis results involved protein interactions to initiate a change in cell activity, such as dopamine receptor activity. The large ribosomal subunit cellular component was upregulated, and plays an important role in protein synthesis. Furthermore, the epithelial cell proliferation biological process was significantly enriched, and is an important component in breast cancer. The GO analysis revealed differences in various aspects of tumor growth and metabolism between the two model groups and indicated the functional changes specific to the human mammary microenvironment.

In the present humanized HB mouse model, immunodeficient mice were used to ensure improved survival of implanted human breast tissues. One limitation to this model is that this mouse model may include a microenvironment without an immune system. However, the mouse immune system is distinct from the human immune system, and immunodeficient mice have acted as a good platform for implanting a human immune system (43-45). Certain efforts have already been made in implanting human immune tissues or cells into immunodeficient mouse models (43-45). Indeed, since the implanted human breast tissues cannot survive physically in the mouse body as in the human body, the HB mouse model is not able to absolutely mimic all the species-specific interactions between human breast cancer cells and the human mammary microenvironment. In addition, future studies may be performed using more cell lines and clinical specimens.

In conclusion, the present study screened and analyzed breast cancer gene expression regulated by the human mammary microenvironment based on a novel human breast mouse model. The various regulated genes showed that the species-specific mammary microenvironment of human origin regulated the gene expression of human breast cancer cells. In future studies, the putative function of these genes in tumor development and the upstream and downstream factors of these genes in the human mammary microenvironment may be explored.

\section{Acknowledgements}

This study was partially supported by the National Natural Science Foundation of China (grant nos. 81172502 and 81302305), Natural Science Foundation of Jiangsu Province (grant nos. BK20131027 and 20151023), Program for Development of Innovative Research Team in the First Affiliated Hospital of NJMU (grant no. IRT-008) and Youth Talent Project (grant no. FRC201308), and was a Project Funded by the Priority Academic Program Development of Jiangsu Higher Education Institutions.

\section{References}

1. Hanash S and Schliekelman M: Proteomic profiling of the tumor microenvironment: Recent insights and the search for biomarkers. Genome Med 6: 12, 2014.

2. Bissell MJ and Hines WC: Why don't we get more cancer? A proposed role of the microenvironment in restraining cancer progression. Nat Med 17: 320-329, 2011.

3. Place AE, Jin Huh S and Polyak K: The microenvironment in breast cancer progression: Biology and implications for treatment. Breast Cancer Res 13: 227, 2011.

4. Swartz MA, Iida N, Roberts EW, Sangaletti S, Wong MH, Yull FE, Coussens LM and DeClerck YA: Tumor microenvironment complexity: Emerging roles in cancer therapy. Cancer Res 72: 2473-2480, 2012.

5. Allred DC and Medina D: The relevance of mouse models to understanding the development and progression of human breast cancer. J Mammary Gland Biol Neoplasia 13: 279-288, 2008.

6. Borowsky AD: Choosing a mouse model: Experimental biology in context-the utility and limitations of mouse models of breast cancer. Cold Spring Harb Perspect Biol 3: a009670, 2011.

7. Mahipal A and Nguyen D: Risks and benefits of phase 1 clinical trial participation. Cancer Control 21: 193-199, 2014.

8. Ross S: Trends in the risks and benefits to patients with cancer in phase 1 clinical trials. JAMA 293: 795, 2005.

9. Macchiarini F, Manz MG, Palucka AK and Shultz LD: Humanized mice: Are we there yet? J Exp Med 202: 1307-1311, 2005.

10. Wang J, Xia TS, Liu XA, Ding Q, Du Q, Yin H and Wang S: A novel orthotopic and metastatic mouse model of breast cancer in human mammary microenvironment. Breast Cancer Res Treat 120: 337-344, 2010.

11. Chen H1, Chen TH, Tseng TF, Lu JT, Kuo CC, Fu SC, Lee WJ, Tsai YF, Huang YY, Chuang EY et al: High-sensitivity in vivo THz transmission imaging of early human breast cancer in a subcutaneous xenograft mouse model. Opt Express 19: 21552-21562, 2011.

12. Zheng MJ, Wang J, Xu L, Zha XM, Zhao Y, Ling LJ and Wang S: Human mammary microenvironment better regulates the biology of human. breast cancer in humanized mouse model. Med Oncol 32: 427, 2015.

13. Xia TS, Wang GZ, Ding Q, Liu XA, Zhou WB, Zhang YF, Zha XM, Du Q, Ni XJ, Wang J, et al: Bone metastasis in a novel breast cancer mouse model containing human breast and human bone. Breast Cancer Res Treat 132: 471-486, 2012.

14. Hurst SA: Declaration of Helsinki and protection for vulnerable research participants. JAMA 311: 1252, 2014.

15. Zheng MJ, Wang J, Chen YW, Xu L, Xue DD, Fu W, Zhang YF, Du Q, Zhao Y, Ling LJ, et al: A novel mouse model of gastric cancer with human gastric microenvironment. Cancer Lett 325: 108-115, 2012.

16. Jones-Bolin S: Guidelines for the care and use of laboratory animals in biomedical research. Curr Protoc Pharmacol 4: 4B, 2012.

17. Livak KJ and Schmittgen TD: Analysis of relative gene expression data using real-time quantitative PCR and the $2^{-\Delta \Delta C T}$ method. Methods 25: 402-408, 2001.

18. Zheng Q and Wang XJ: GOEAST: A web-based software toolkit for Gene Ontology enrichment analysis. Nucleic Acids Res 36: W358-W363, 2008.

19. Hulsegge I, Kommadath A and Smits MA: Globaltest and GOEAST: Two different approaches for gene ontology analysis. BMC Proc 3 (Suppl 4): S10, 2009.

20. Kanehisa M and Goto S: KEGG: Kyoto encyclopedia of genes and genomes. Nucleic Acids Res 28: 27-30, 2000. 
21. Campbell JJ, Botos LA, Sargeant TJ, Davidenko N, Cameron RE and Watson CJ: A 3-D in vitro co-culture model of mammary gland involution. Integr Biol (Camb) 6: 618-626, 2014

22. Król M, Pawłowski KM, Szyszko K, Maciejewski H, Dolka I, Manuali E, Jank M and Motyl T: The gene expression profiles of canine mammary cancer cells grown with carcinoma-associated fibroblasts (CAFs) as a co-culture in vitro. BMC Vet Res 8: 35, 2012.

23. Casbas-Hernandez P, Fleming JM and Troester MA: Gene expression analysis of in vitro cocultures to study interactions between breast epithelium and stroma. J Biomed Biotechnol 2011: 520987, 2011.

24. Rozenchan PB, Carraro DM, Brentani H, de Carvalho Mota LD, Bastos EP, e Ferreira EN, Torres CH, Katayama ML, Roela RA, Lyra EC, et al: Reciprocal changes in gene expression profiles of cocultured breast epithelial cells and primary fibroblasts. Int J Cancer 125: 2767-2777, 2009.

25. Wiltshire C, Matsushita M, Tsukada S, Gillespie DA and May GH: A new c-Jun N-terminal kinase (JNK)-interacting protein, Sab (SH3BP5), associates with mitochondria. Biochem J 367: $577-585,2002$

26. Hsu YM, Chen YF, Chou CY, Tang MJ, Chen JH, Wilkins RJ, Ellory JC and Shen MR: KCl cotransporter-3 down-regulates E-cadherin/beta-catenin complex to promote epithelial-mesenchymal transition. Cancer Res 67: 11064-11073, 2007.

27. Hsu YM, Chou CY, Chen HH, Lee WY, Chen YF, Lin PW, Alper SL, Ellory JC and Shen MR: IGF-1 upregulates electroneutral $\mathrm{K}-\mathrm{Cl}$ cotransporter $\mathrm{KCC} 3$ and $\mathrm{KCC} 4$ which are differentially required for breast cancer cell proliferation and invasiveness. J Cell Physiol 210: 626-636, 2007.

28. Wang Z and Ouyang G: Periostin: A bridge between cancer stem cells and their metastatic niche. Cell Stem Cell 10: 111-112, 2012.

29. Kyutoku M, Taniyama Y, Katsuragi N, Shimizu H, Kunugiza Y, Iekushi K, Koibuchi N, Sanada F, Oshita Y and Morishita R: Role of periostin in cancer progression and metastasis: Inhibition of breast cancer progression and metastasis by anti-periostin antibody in a murine model. Int J Mol Med 28: 181-186, 2011.

30. Miyajima N, Maruyama S, Nonomura K and Hatakeyama S: TRIM36 interacts with the kinetochore protein CENP-H and delays cell cycle progression. Biochem Biophys Res Commun 381: 383-387, 2009.

31. Goyal J, Smith KM, Cowan JM, Wazer DE, Lee SW and Band V: The role for NES1 serine protease as a novel tumor suppressor. Cancer Res 58: 4782-4786, 1998.

32. Liu W, Morito D, Takashima S, Mineharu Y, Kobayashi H, Hitomi T, Hashikata H, Matsuura N, Yamazaki S, Toyoda A, et al: Identification of RNF213 as a susceptibility gene for moyamoya disease and its possible role in vascular development. PLoS One 6: e22542, 2011.

33. Mukhopadhyay P, Reddy MK, Singla-Pareek SL and Sopory SK: Transcriptional downregulation of rice rpL32 gene under abiotic stress is associated with removal of transcription factors within the promoter region. PLoS One 6: e28058, 2011.
34. Kuo SH, Chou CH, Cheng AL, Wang CW, Chen $\mathrm{YH}$ and Chen RJ: Expression of BCL10 in cervical cancer has a role in the regulation of cell growth through the activation of NF- $\kappa \mathrm{B}$-dependent cyclin D1 signaling. Gynecol Oncol 126: 245-251, 2012.

35. Buganim Y, Goldstein I, Lipson D, Milyavsky M, Polak-Charcon S, Mardoukh C, Solomon H, Kalo E, Madar S, Brosh R, et al: A novel translocation breakpoint within the BPTF gene is associated with a pre-malignant phenotype. PLoS One 5: e9657, 2010.

36. Vehviläinen P, Hyytiäinen $M$ and Keski-Oja J: Latent transforming growth factor-beta-binding protein 2 is an adhesion protein for melanoma cells. J Biol Chem 278: 24705-24713, 2003.

37. Hyytiäinen M and Keski-Oja J: Latent TGF-beta binding protein LTBP-2 decreases fibroblast adhesion to fibronectin. J Cell Biol 163: 1363-1374, 2003.

38. Sutherland LC, Rintala-Maki ND, White RD and Morin CD: RNA binding motif (RBM) proteins: A novel family of apoptosis modulators? J Cell Biochem 94: 5-24, 2005

39. Jögi A, Brennan DJ, Rydén L, Magnusson K, Fernö M, Stål O, Borgquist S, Uhlen M, Landberg G, Påhlman S, et al: Nuclear expression of the RNA-binding protein RBM3 is associated with an improved clinical outcome in breast cancer. Mod Pathol 22: 1564-1574, 2009.

40. Donoghue M, Hsieh F, Baronas E, Godbout K, Gosselin M, Stagliano N, Donovan M, Woolf B, Robison K, Jeyaseelan R, et al: A novel angiotensin-converting enzyme-related carboxypeptidase (ACE2) converts angiotensin I to angiotensin 1-9. Circ Res 87: E1-E9, 2000.

41. Haga S, Yamamoto N, Nakai-Murakami C, Osawa Y, Tokunaga K, Sata T, Yamamoto N, Sasazuki T and Ishizaka Y: Modulation of TNF-alpha-converting enzyme by the spike protein of SARS-CoV and ACE2 induces TNF-alpha production and facilitates viral entry. Proc Natl Acad Sci USA 105: 7809-7814, 2008

42. The Gene Ontology Consortium: Gene Ontology Consortium: Going forward. Nucl Acids Res 43: D1049-D1056, 2015.

43. Yamanaka N, Wong CJ, Gertsenstein M, Casper RF, Nagy A and Rogers IM: Bone marrow transplantation results in human donor blood cells acquiring and displaying mouse recipient class I MHC and CD45 antigens on their surface. PLoS One 4: e8489, 2009.

44. Fleming JM, Miller TC, Kidacki M, Ginsburg E, Stuelten $\mathrm{CH}$, Stewart DA, Troester MA and Vonderhaar BK: Paracrine interactions between primary human macrophages and human fibroblasts enhance murine mammary gland humanization in vivo. Breast Cancer Res 14: R97, 2012.

45. Chow T, Whiteley J, Li M and Rogers IM: The transfer of host MHC class I protein protects donor cells from NK cell and macrophage-mediated rejection during hematopoietic stem cell transplantation and engraftment in mice. Stem Cells 31: 2242-2252, 2013. 